\title{
The Relation between Helicobacter Pylori Density and Gastritis Severity
}

\section{Serhat Sayin*}

Department of Internal Medicine, Training and Research Hospital, Aksaray University, Turkey

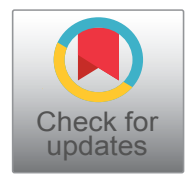

*Corresponding author: Serhat Sayin, Department of Internal Medicine, Training and Research Hospital, Aksaray University, Turkey

\begin{abstract}
Background/Aims: Helicobacter pylori affects many individuals in developing countries. Inflammation caused by helicobacter pylori differs depending on the virulence factors, density and host tissue response of the bacteria. This study is intended to investigate the relation between density of helicobacter pylori colonization in gastric mucosa in biopsy specimens and gastric mucosal inflammation severity.

Materials and methods: Our study included 685 patients who applied to the hospital with dyspeptic complaints and had gastroscopy between the dates of January the $1^{\text {st }} 2017$ and January the $1^{\text {st }} 2018$. Histopathologic results of endoscopic biopsy specimens of these patients were retrospectively screened. Inflammatory severity and helicobacter pylori intensity were assessed by Sydney scoring.

Results: $68.6 \%$ of the patients were infected with Helicobacter pylori. As the intensity of inflammation increased, the intensity of Helicobacter pylori increased as well. The relation between the intensity of Helicobacter pylori and the severity of inflammation was statistically significant $(p$ $<0.001)$.
\end{abstract}

Conclusion: Helicobacter pylori infection increases gastric inflammation.

\section{Keywords}

Helicobacter pylori, Gastritis, Endoscopic biopsy

\section{Introduction}

Helicobacter pylori (H. pylori/Hp) is a microaerophilic gram negative bacilli initially detected in the antral gastric mucosa by Warren and Marshall [1]. Today, around half of the world's population is infected with Helicobacter pylori [2]. Helicobacter pylori is most commonly found in the antrum. Bacilli is placed deep into the mucosa gelatin covering the gastric mucosa or be- tween the mucus layer and the gastric epithelium. $\mathrm{H}$. Pylori causes mucosal inflammation with proinflammatory factors that it released and it also spoils mucus layer with released enzymes. The inflammation caused by helicobacter pylori depends on the virulence factors, the density and the host tissue of the bacterium [3]. In various studies, $H$. pylori has been shown to be associated with gastritis, peptic ulcer, gastric carcinoma and Mucosal Associated Lymphoid Tissue (MALT) lymphoma [4-6].

Gastritis is an important pathological condition that causes gastric atrophy and cancer characterized by infiltration of inflammatory cells, especially lymphocytes and plasma cells, as well as neutrophils in the lamina propria. Gastritis does not have a specific finding that can be detected by endoscopic imaging $[7,8]$. However, histopathologic examination of the specimens taken from the tissue by endoscopy is accepted as the gold standard in the diagnosis of gastritis. The Sydney system is a good scoring system for histopathological evaluation and classification of gastritis. Sydney scoring is a classification based on topographic, morphological and etiological criteria of gastritis. It was accepted by consensus of gastroenterologist and pathologists at the World Congress of Gastroenterology in Sydney in 1990. The most important feature of this system is that the changes in the gastric mucosa are graded as five major histologic features (chronic inflammation, neutrophil activity, glandular atrophy, intestinal metaplasia and H. pylori density) [9]. This classification facilitates the clinical, endoscopic and morphological association of gastritis. It has been reported that there is a good correlation between polymorphonuclear cell infiltration 
and $H$. pylori infection histologically with the updated Sydney system [10].

This study is intended to investigate the relation between the intensity of Helicobacter pylori colonization and the severity of gastric mucosal inflammation in biopsy specimens taken from the gastric mucosa.

\section{Materials and Methods}

This cross-sectional analytical study was carried out in Aksaray at Training and Research hospital, Internal Diseases and Gastroenterology outpatient clinics between the dates of January the $1^{\text {st }} 2017$ and January the $1^{\text {st }}, 2018$ on 685 patients who were admitted with dissipative complaints and underwent upper gastrointestinal endoscopy. The study data were obtained by retrospectively examining the histopathological results of endoscopic biopsy materials of patients.

The histopathological diagnosis and classification of gastritis in our study was assessed by Sydney scoring. In

Table 1: The evaluation of Helicobacter pylori density.

\begin{tabular}{|l|l|}
\hline Gradation & Description \\
\hline 0 & No H. pylori \\
\hline 1 & $\begin{array}{l}\text { Singly or in small groups in less than } 1 / 3 \text { of the } \\
\text { mucosa surface }\end{array}$ \\
\hline 2 & $\begin{array}{l}\text { Between } 1 \text { and } 3 \\
\text { Wide or in big groups in more than } 2 / 3 \text { of } \\
\text { mucosa surface }\end{array}$ \\
\hline 3 & \\
\hline
\end{tabular}

Table 2: The frequency of $H$. pylori and other histopathological findings.

\begin{tabular}{|l|l|l|}
\hline Parameters & n & \% \\
\hline H. pylori & \multicolumn{2}{l|}{} \\
\hline Positive & 470 & 68.6 \\
\hline Negative & 215 & 31.4 \\
\hline Pathological diagnosis & \multicolumn{2}{|l|}{} \\
\hline Chronic active gastritis & 383 & 55.9 \\
\hline Chronic gastritis & 302 & 44.1 \\
\hline Inflammation severity & \multicolumn{2}{|l|}{} \\
\hline Mild & 235 & 34.3 \\
\hline Moderate & 265 & 38.7 \\
\hline Severe & 185 & 27.0 \\
\hline Metaplasia & & \\
\hline Yes & 94 & 86.3 \\
\hline No & 591 & 13.7 \\
\hline
\end{tabular}

our study, inflammation grade was evaluated as as mild $(<1 / 3)$, moderate $(1 / 3-2 / 3)$, and severe $(>2 / 3)$ according to the infiltration of neutrophils in lamina propria or surface epithelium.

The existence of a Helicobacter pylori was investigated by May Grünwald Giemsa stain in mucosa samples obtained from antrum and its density was evaluated (Table 1).

In evaluation of the obtained data, SPSS (Statistical Package for Social Sciences) for Windows 20.0 program was used for the statistical analysis. Descriptive statistics for continuous variables were given in terms of mean and standard deviation, and descriptive statistics for categorical data were given in frequency and percentage. The Chi-Square test was used to compare the data in the categorical structure. Correlation between parameters was done by Pearson correlation analysis. Correlation coefficient ( $r$ ) was evaluated as weak between $0.00-0.24$, moderate between $0.25-0.49$, strong between $0.50-0.74$, very strong between $0.75-1.00$. The results were evaluated in a confidence interval of $95 \%$ and in a significance level of $p<0.05$.

\section{Results}

In our study, $65.8 \%(n=451)$ of 685 patients were female and $34.2 \%(n=234)$ were male. Mean age of all patients was $47.51 \pm 15.61$ year $(47.79 \pm 15.79$ in women and $46.99 \pm 15.28$ in men. $68.6 \%(n=470)$ of the patients were infected with $\mathrm{H}$. Pylori. Histopathologic results of the patients were presented on the table (Table 2).

No statistically significant relationship was found between $H$. pylori presence and metaplasia status in our study $\left(\chi^{2}=2.416, p=0.120\right)$. There was a significant relationship between the severity of inflammation and the intensity of $H$. pylori in our study. As the intensity of $H$. pylori increased, the intensity of gastric inflammation increased as well (Table 3). The frequency and intensity of $H$. pylori in chronic active gastritis was statistically significantly higher than that of chronic gastritis (Figure 1). As the severity of inflammation increased, $H$. pylori frequency also increased (Figure 2).

\section{Discussion}

The prevalence of $H$. pylori is quite high throughout the world in developed and also in developing countries like our country. $H$. pylori positivity was $68 \%$ in our study.

Table 3: The relation of H.pylori intensity with degree of inflammation $\left(x^{2}=3.940, p<0.001\right)$.

\begin{tabular}{|c|c|c|c|c|c|c|c|c|}
\hline & \multicolumn{2}{|c|}{ Hp (-) } & \multicolumn{2}{|c|}{$\mathrm{Hp}(+)$} & \multicolumn{2}{|c|}{ Hp (++) } & \multicolumn{2}{|c|}{ Hp (+++) } \\
\hline & $\mathbf{n}$ & $\%$ & n & $\%$ & $\mathbf{n}$ & $\%$ & $\mathbf{n}$ & $\%$ \\
\hline Mild inflammation & 155 & 72.1 & 61 & 45.2 & 19 & 8.3 & 0 & 0.0 \\
\hline Moderate inflammation & 43 & 20.0 & 71 & 52.6 & 127 & 55.7 & 24 & 22.4 \\
\hline Severe inflammation & 17 & 7.9 & 3 & 2.2 & 82 & 36.0 & 83 & 77.6 \\
\hline Total & 215 & 100.0 & 135 & 100.0 & 228 & 100.0 & 107 & 100.0 \\
\hline
\end{tabular}




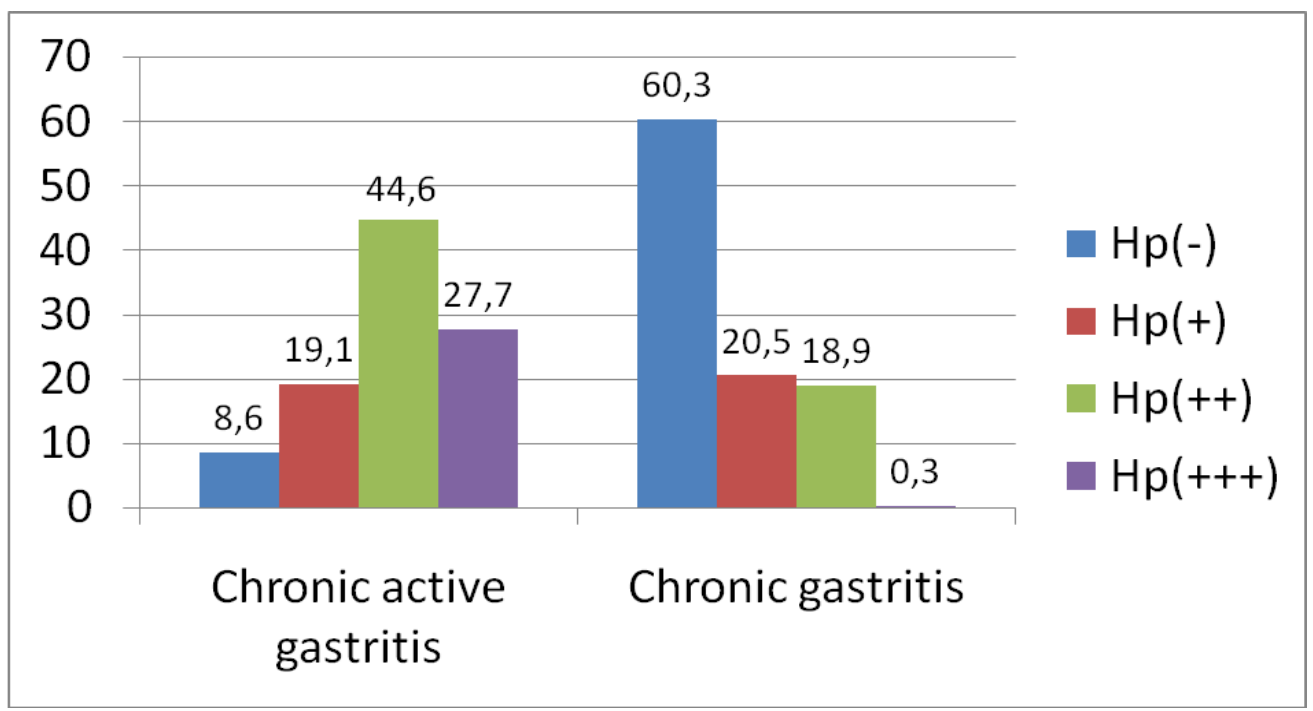

Figure 1: The degree of $H$. pylori intensity in the chronic gastritis and chronic active gastritis $\left(X^{2}=2.092, p<0.001\right)$.

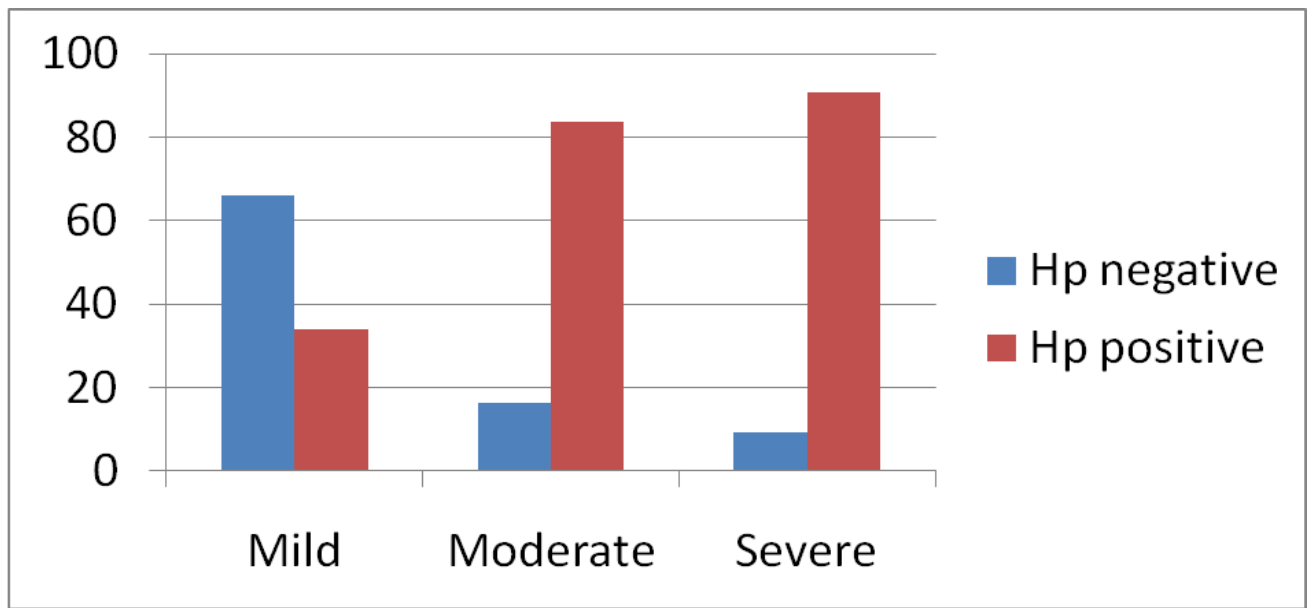

Figure 2: The relation of $H$. pylori frequency with degree of inflammation $\left(X^{2}=2.010, p<0.001\right)$.

In a study by Konakcl, et al. in our country, H. pylori positivity was reported to be $50 \%$ [11]. In a study performed in Romania by Olar, et al. H. pylori prevalence was found to be $63 \%$ [12]. In a study in Japan, Nomura, et al. found out $H$. pylori positivity as $62 \%$ [13].

$H$. pylori plays a major role in the pathogenesis of gastric diseases (gastritis, ulcer, cancer) due to the fact that it causes mucosal destruction. However, it is not known exactly how the mucosal damage develops with $H$. pylori. It is thought that proteases released by $H$. Pylori and gastric glycoprotein breaks down mucus structure and as a result, acidic gastric juice passes through this mucous membrane and causes mucosal damage [14]. Cell damage results from the direct toxic effect of ammonia, which is released into the gastric lumen by bacterial urease activity. It is also known that the various cytokines and chemotactic factors secreted by bacteria are also direct cytopathic and inflammatory initiating effects.

While there was no significant relationship between H. pylori and inflammation grade in various studies
$[15,16]$, there was a significant correlation in some other studies $[17,18]$. There was a statistically significant relation between the intensity of $H$. pylori and the severity of inflammation in our study. As the intensity of $H$. pylori increased, the severity of inflammation increased as well. In a study by Yakoob, et al. a significant relationship was found between $H$. pylori colonization intensity and chronic gastritis activity [19]. As in our study, Basir, et al. also found a significant relationship between $H$. pylori colonization intensity and chronic gastritis activity [20]. In a study performed by means of Histopathological examination of endoscopic biopsy specimens of 461 patients, Türkay, et al. reported that as the intensity of $H$. pylori increased, the intensity of inflammation increased, too [21]. In a study conducted by Alagöz, et al. a significant correlation was observed between $H$. pylori severity and lymphoplasmacytic cell infiltration and inflammation activation [22]. In contrast, in a study of 272 gastric biopsy specimens by Ardakani, et al. no significant relationship was found between the density of $H$. pylori and the severity of chronic gastritis activity [3]. Again, Choudhary, et al. found no significant 
relation between $H$. pylori density and chronic gastritis activity [23].

\section{Conclusion}

As a result, studies have shown a relationship between the intensity of $H$. pylori and the severity of gastritis. Histopathological examination and classification of gastritis are important for accurate diagnosis of $H$. pylori infection affecting upper gastrointestinal system by various complications. Proper treatment of $H$. pylori infection can prevent gastritis and its complications.

\section{References}

1. Warren JR, Marshall B (1983) Unidentified curved bacillus on gastric epithelium in active chronic gastritis. Lancet 1 : 1273-1275.

2. Hunt RH, Xiao SD, Megraud F, Leon-Barua R, Bazzoli F, et al. (2011) Helicobacter pylori in developing countries. World gastroenterology organization global guideline. J Gastrointestin Líver Dis 3: 299-304.

3. Ardakani A, Mohammadizadeh F (2006) The study of relationship between helicobacter pylori density in gastric mucosa and the severity and activity of chronic gastritis. JRMS 11: 282.

4. Hooi JKY, Lai WY, Ng WK, Suen MMY, Underwood FE, et al. (2017) Global prevalence of helicobacter pylori infection: Systematic review and meta-analysis. Gastroenterology 153: $420-429$.

5. Wang C, Yuan Y, Hunt RH (2007) The association between helicobacter pylori infection and early gastric cancer: a metaanalysis. Am J Gastroenterol 102: 1789-1798.

6. Ferreira AC, Isomoto $H$, Moriyama M, Fujioka $T$, Machado $\mathrm{JC}$, et al. (2008) Helicobacter and gastric malignancies. Helicobacter 13: 28-34.

7. Calabrese C, Di Febo G, Brandi G, Morselli-Labate AM, Areni A, et al. (1999) Correlation between endoscopic features of gastric antrum, histology and helicobacter pylori infection in adults. Ital J Gastroenterol Hepatol 31: 359-365.

8. Redeen S, Petersson F, Jonsson KA, Borch K (2003) Relationship of gastroscopic features to histological findings in gastritis and helicobacter pylori infection in a general population sample. Endoscopy 35: 946-950.

9. Ugras N, Yerci O (2012) Histological evaluation of gastric biopsies according to Sydney classification and comparison of chronic gastritis mucosal histological findings by age group. Journal of Contemporary Medicine 2: 173-178.

10. Dixon MF, Genta RM, Yardley JH, Correa P (1996) Classification and grading of gastritis. The updated Sydney system. International Workshop on the Histopathology of Gastritis, Houston 1994. Am J Surg Pathol 20: 1161-1181.
11. Konakci N, Gülten M, İbanoğlu MS, Yorulmaz H, Veyseloğlu L, et al. (2010) Kronik aktif gastritli olgularda helicobacter pylori sıklığı. Uludağ Üniversitesi Tıp Fakültesi Dergisi 36: 7-10.

12. Olar L, Mitruţ $P$, Florou C, Mălăescu GD, Predescu OI, et al. (2017) Evaluation of helicobacter pylori infection in patients with eso-gastro-duodenal pathology. Rom J Morphol Embryol 58: 809-815.

13. Nomura S, Terao S, Adachi K, Kato T, Ida K, et al. (2013) Endoscopic diagnosis of gastric mucosal activity and inflammation. Dig Endosc 25: 136-146.

14. Hui PK, Chan WY, Cheung PS, Chan JK, Ng CS (1992) Pathologic changes of gastric mucosa colonized by Helicobacter pylori. Hum Pathol 23: 548-556.

15. Petross CW, Appleman MD, Cohen H, Valenzuela JE, Chandrasoma P, et al. (1988) Prevalence of campylobacter pylori and association with antral mucosal histology in subjects with and without upper gastrointestinal symptoms. Dig Dis Sci 33: 649-653.

16. Price $A B$, Levi J, Dolby JM, Dunscombe PL, Smith $A$, et al. (1985) Campylobacter pyloridis in peptic ulcer disease: Microbiology, pathology and scanning electron microscopy. Gut 26: 1183-1188.

17. Andersen LP, Holck S, Povlsen CO, Elsborg L, Justesen T (1987) Campylobacter pyloridis in peptic ulcer disease: I. Gastric and duodenal infection caused by $\mathrm{c}$. pyloridis: Histopathologic and microbiologic findings. Scand J Gastroenterol 22: 219-224.

18. Wyatt JE, Rathbone BJ, Heatley RV (1996) Local immune response to gastric campylobacter in non-ulcer dyspepsia. J Clin Pathol 39: 863-870.

19. Yakoob MY, Hussainy AS (2010) Chronic gastritis and helicobacter pylori: A histopathological study of gastric mucosal biopsies. J Coll Physicians Surg Pak 20: 773-775.

20. Basir HRG, Ghobakhlou M, Akbari P, Dehghan A, Rabiei MAS (2017) Correlation between the intensity of helicobacter pylori colonization and severity of gastritis. Gastroenterol Res Pract 10: 1155-1159.

21. Turkay C, Erbayrak M, Bavbek N, Yenidünya $S$, Eraslan E, et al. (2011) Helicobacter pylori and histopathological findings in patients with dyspepsia. Turk J Gastroenterol 22: $122-127$.

22. Alagoz S, Turkay C, Yonem O (2002) The relationship between helicobacter pylori intensity and histopathological findings in cases with chronic gastritis and duodenal ulcer. Turk J Gastroenterol 13: 98-102.

23. Choudhary CK, Bhanot UK, Agarwal A, Garbyal RS (2001) Correlation of $h$. pylori density with grading of chronic gastritis. Indian J Pathol Microbiol 44: 325-328. 